\title{
CONSTRUCTION OF TOOL FOR MACHINING HARD MATERIALS
}

\author{
Michal Povolny, Tomas Zatloukal \& Jan Rehor
}
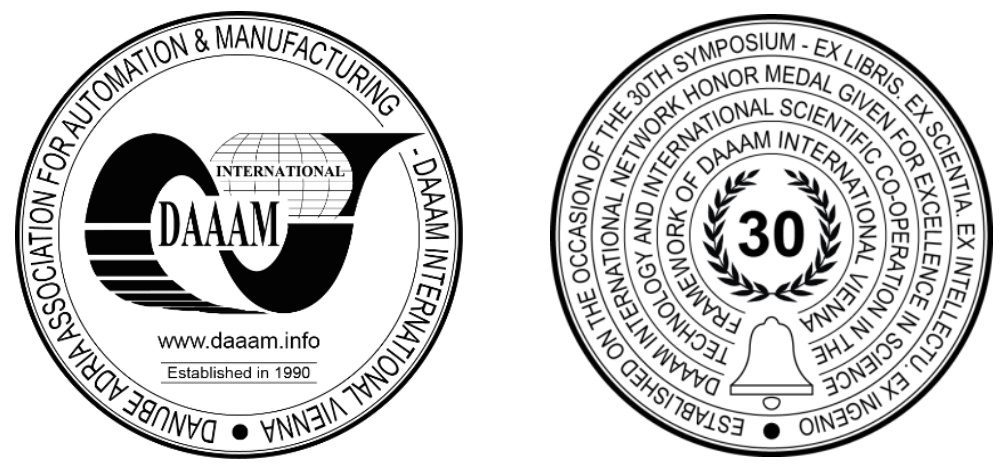

This Publication has to be referred as: Povolny, M[ichal]; Zatloukal, T[omas] \& Rehor, J[an] (2021). Construction of Tool for Machining Hard Materials, Proceedings of the 32nd DAAAM International Symposium, pp.0299-0305, B. Katalinic (Ed.), Published by DAAAM International, ISBN 978-3-902734-33-4, ISSN 1726-9679, Vienna, Austria DOI: $10.2507 / 32$ nd.daaam.proceedings.043

\begin{abstract}
This paper is based on the knowledge gained in the field of development and construction of tools for machining very hard and difficult to machine materials based on thermal spraying (for example NiCrBSi, Fe13Cr, Stellite 6 and others) and printed materials such as Inconel 718. Due to the methods of coating production, using heat technologies and their specific composition due to increased hardness and wear resistance, their conventional machining is very difficult. A common way of machining the coatings thus formed is by grinding. However, grinding productivity is low and production costs are relatively high. Therefore, it is necessary to explore the possibilities of machinability of thermal sprays and increase the cutting ability of tools, especially through more productive approaches and technologies. When machining thermal sprays, a large heat is also generated in the cutting area, which further helps to wear the tool edge faster. In the conventional method of machining by turning and milling, cutting materials such as cubic boron nitride (CBN) or polycrystalline diamond (PKD) are often used, precisely because of their high hardness or heat resistance.
\end{abstract}

Keywords: tool design; construction of tool; machining; thermal spraying

\section{Introduction}

Certain problems arise when milling or milling difficult to machine materials, especially hot-dipped materials. One of the problems is plastic deformation affecting the base material due to the effect of the small depth of cut. This poses a risk of possible cracking or partial tearing of the hot-dip coating. Another issue is the high temperature in the cutting area, which causes in particular an increase in the wear intensity of the inserts. This leads to a deterioration of machinability and especially to an increase in the wear intensity of the insert. High hardness also increases the requirements for tool rigidity due to high cutting forces. [1] [2] [17]

Because of plastic deformation and the need for very small cutting depths of up to $0.5 \mathrm{~mm}$, tool tip machining is a problem. Therefore, it is advisable to use a so-called "linear cutting edge". This way the tool does not work through the tip, but the whole length of the cutting edge can be used. Due to the small cutting edge radius, very little wear can be achieved and it is also possible to use the entire length of the cutting edge and thus increase the life of the insert. [1] [2] [17] 
On the basis of the experiments already carried out, high wear and low lifetime of the inserts during hot spray machining by conventional turning method, i.e. in the case where the tip of the insert enters the cutting point, was evaluated as one of the problems. Based on these findings, due to the high temperature of the cutting point and the low life of the insert, it is proposed to optimize the cutting tool to bring the coolant as far as possible into the cutting point and to use the full length of the inserts (linear cutting edge) to eliminate the aforementioned shortcomings. [1][2]

Thus, the main idea is to make the wafer cooling more efficient and to use the full length of the cutting edge of the wafer, thus making the machining of the hot stampings more efficient and increasing the life of the wafer. The next point is then to increase the rigidity of the tool and to develop a tool that meets the above requirements. [1][2]. Since the design of the ideal cooling and placement of the insert so that the entire length of the cutting edge can be utilized while maintaining or even increasing tool stiffness is a rather complex design task, the use of topological optimization using additive technologies appears to be the ideal design method. [1][2] [15]

\section{Summary of the current state in the field of printed tools and cooling}

When machining certain types of materials, it is necessary to use a cooling or lubricating medium during the cutting process. During cutting, heat is generally generated by the friction of the surfaces between the tool and the material being cut, as well as by plastic deformation at the point of chip formation. The dissipation and reduction of heat at the cutting point then has positive results on the durability of the cutting edge and the resulting quality of the machined surface. The cooling system then has positive effects on the actual cutting, lubrication and cleaning of the cutting area. The medium, usually a liquid, can be fed to the cutting point in a conventional external way. The second way (internal), which is increasingly used nowadays, is to feed it directly through the cutting tool, which increases the cooling efficiency and thus the machining performance, thanks to the possibility of more efficient and precise delivery of the fluid to the cutting point. The fluid can be supplied at standard or elevated pressure, referred to as high pressure cooling. Where this type of high pressure cooling allows better penetration of the fluid between the chip and the tool face/back, thus aiding chip separation and better heat dissipation from the cutting point. [3] [17]

Nowadays it is common to design tools with internal cooling, such as sintered carbide drills, where it is possible to produce cooling channels in the helix, or milling and turning knives with straight drilled channels. The disadvantage is the impossibility of bringing the channels to exactly the required locations to make cooling more efficient. It is this disadvantage that is eliminated by topological optimization using additive technology, where it is possible to achieve the ideal shape and course of the channel as well as its precise alignment to achieve the most efficient cooling and reduce turbulent fluid flow in the channel and fluid pressure losses. [3] [17]

The following text describes the state of the art in the field of process fluid feed solutions and control options, as well as tools constructed using topological optimization and additive technologies. The first tool that is already conventionally offered is the CoroMill® 390 lightweight cutter manufactured using additive technology by Sandvik Coromant. In designing the cutter, topological optimization was used to create an optimum cutter design to achieve minimum weight and compactness of the tool. The cutter is printed in titanium alloy, which further helps to reduce the resulting weight. The lower overall weight in this case helps to minimize vibrations and increase machining safety when machining with long tool unloading, thus also increasing machining productivity. The milling cutter is particularly used in milling operations with long tool unloading, where the adapter houses the damping mechanism. The low weight of the tool as well as the short distance between the damping mechanism and the tool cutting edge thus helps to reduce vibrations and thus increase the performance and improve the safety of the machining process. The milling cutter can be used for face and side milling of deep corners, cavities and grooves and is available in 40 or 50mm diameter, with a choice of three or four teeth with uneven tooth spacing and internal coolant supply. [4]
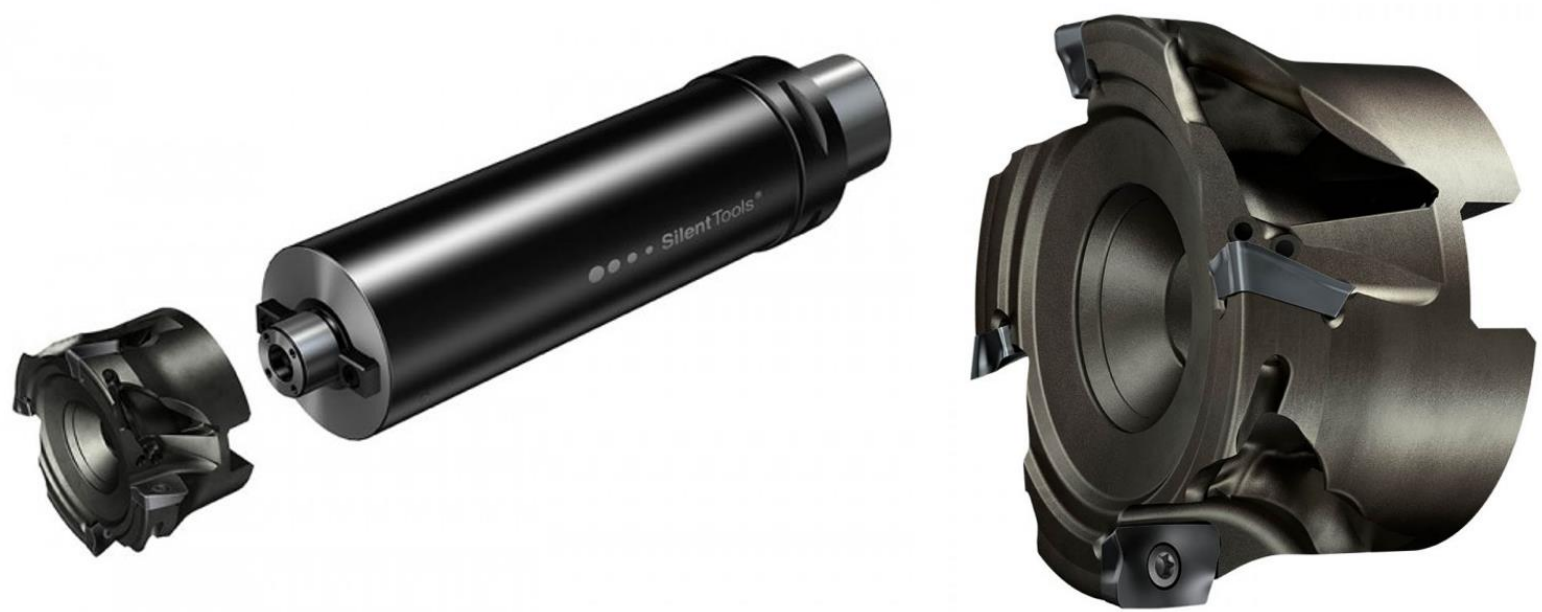

Fig. 1. Sandvik CoroMill 390 [4] 
LMT's tool is based on a similar principle. This tool uses additive technology to create curved cooling channels. This delivers the fluid exactly where it is needed. According to tests conducted, this design change has resulted in a $50 \%$ increase in VBD life when milling titanium. The following question is a prototype of LMT's coolant channel tool. [5]

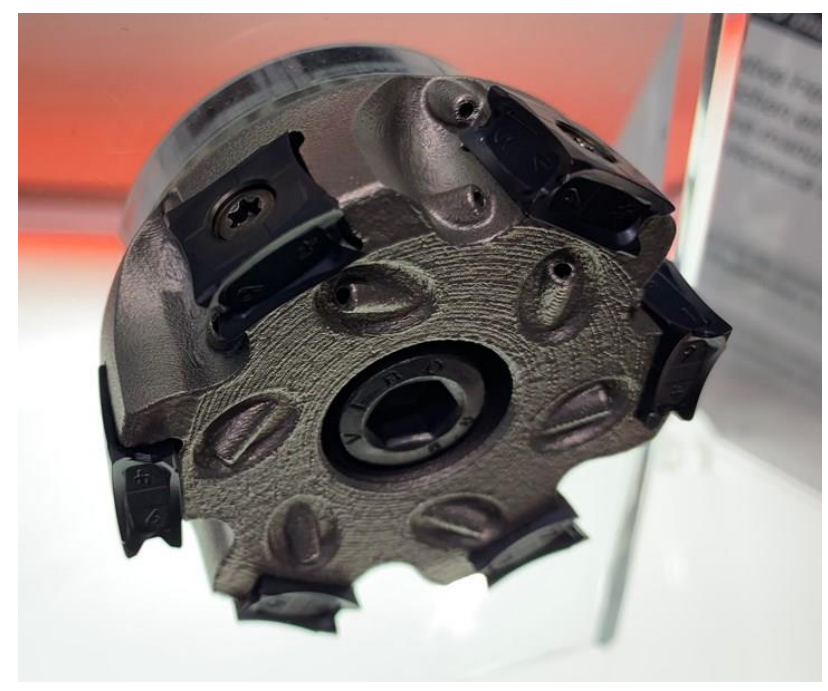

Fig. 2. A tool developed using 3D printing and optimization of cooling channels [5]

Makino also has a specific approach to lightweighting the tool. The tool pictured below is designed for machining gearboxes and motor housings. Given the size of the tool, the aim is to make it as light as possible. Particularly because of the ability to change cutting speeds quickly and also to move the tool quickly in the tool magazine. Makino uses additive technologies in conjunction with a carbon fibre composite tool body. This achieves very low weight while maintaining high strength and rigidity. [5]

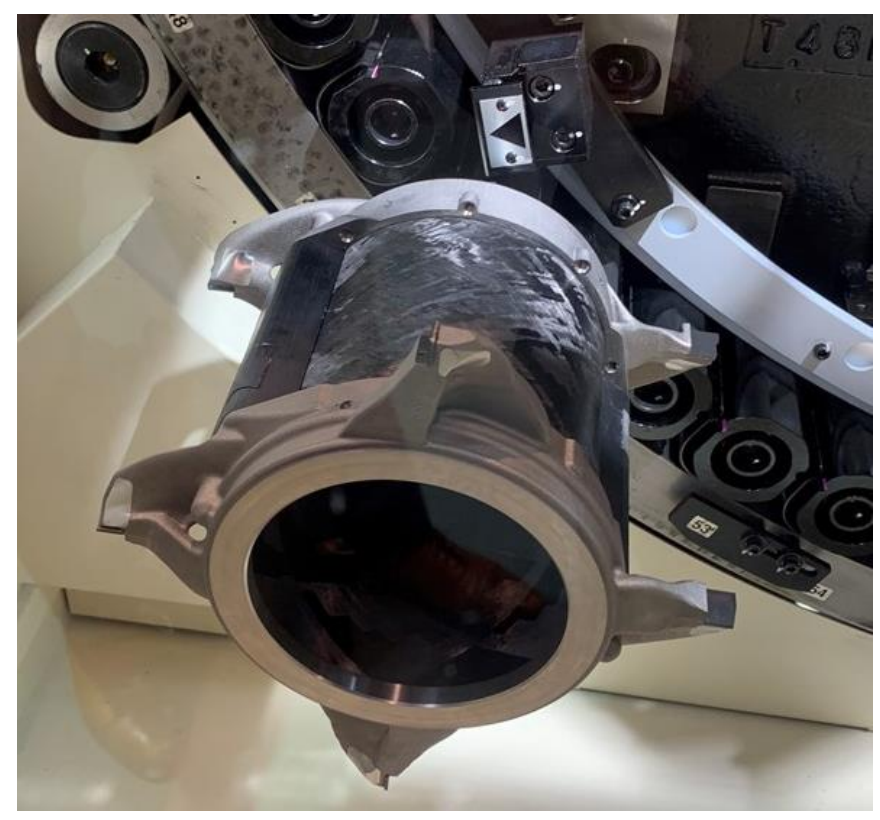

Fig. 3. Lightweight tool with composite body [5]

Another tool that is based on the principle of optimization and 3D printing is a cutter developed at the University of West Bohemia. This milling machine is based on the principle of a bar construction, where the individual insert carriers and the tool body are connected by spacers and struts are incorporated between them. This achieves sufficient rigidity of the tool while reducing its weight as much as possible. The body of the tool is also fitted with nozzles which are directed onto the face and back of the interchangeable inserts, serving to cool the tool more efficiently. The entire tool is printed in tool steel, due to the difficulty of machining and high cost in the case of titanium printing. The tool is designed primarily for roughing operations. The tool's bar structure is not manufacturable by conventional manufacturing methods, so additive manufacturing is used. Another advantage is the material savings, up to $60 \%$ less weight compared to standard tools, while maintaining the rigidity and strength of the tool. [6] [7] [14] [16] 


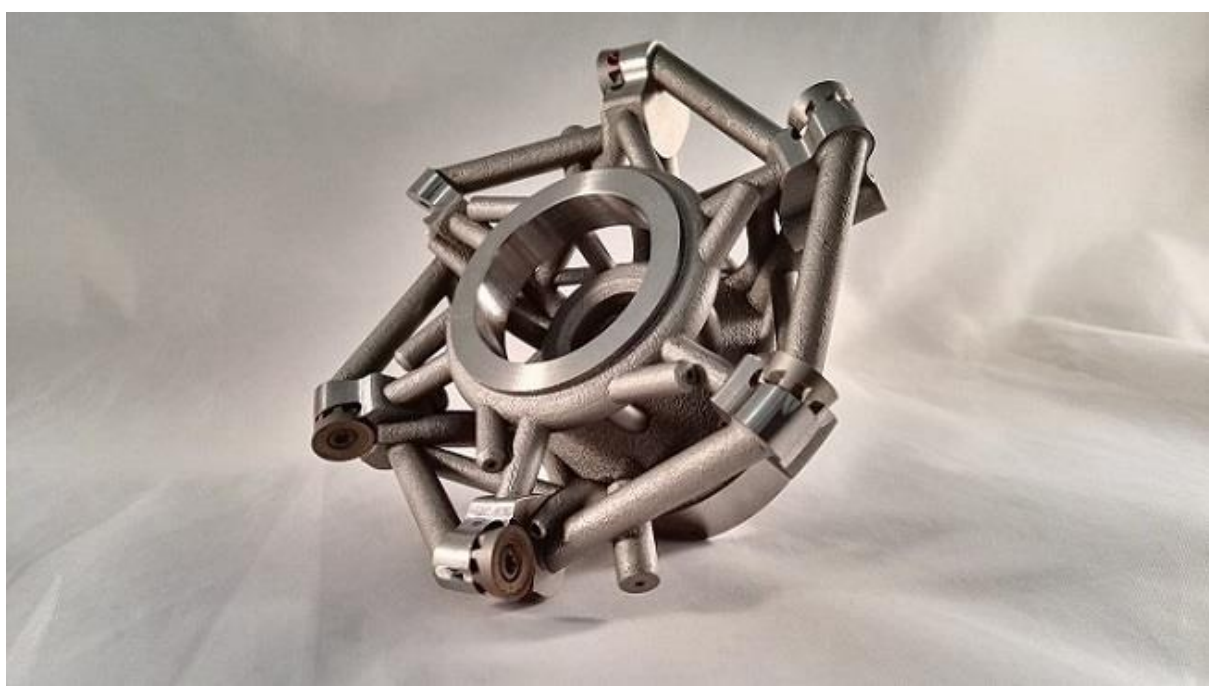

Fig. 4. KRAKEN milling head [7]

The following patents are based on the principle of controlling, opening and closing the cooling channels. The first patent described in US8696252 is a cutter with an adjustable cooling mechanism. Where, on the circumference of the tool, helically mounted inserts with cooling channels are fed to the inserts faces. The tool is designed as a conventional cutter without the use of optimization and 3D printing. A center pin is located in the center of the cutter and serves as a mechanism to open and close certain cooling channels. The pin is hollow and has grooves in which the outlet of the cooling channels is located. These can then be further connected to the channels in the body of the tool. The grooves on the body of the bolt can be provided with a sealing ring and thus the flow of coolant into the tool body and to the replaceable inserts can be sealed (interrupted). The stud is threaded and the stud must be unscrewed each time the cooling is adjusted, meaning adding or rearranging the seal. This solution is therefore quite tedious, especially in a situation where there is a frequent need to open and close certain channels according to the type of material being machined, the machining method and the cutting conditions. The following figure shows a prototype tool with a pin controlling the fluid supply. [8]

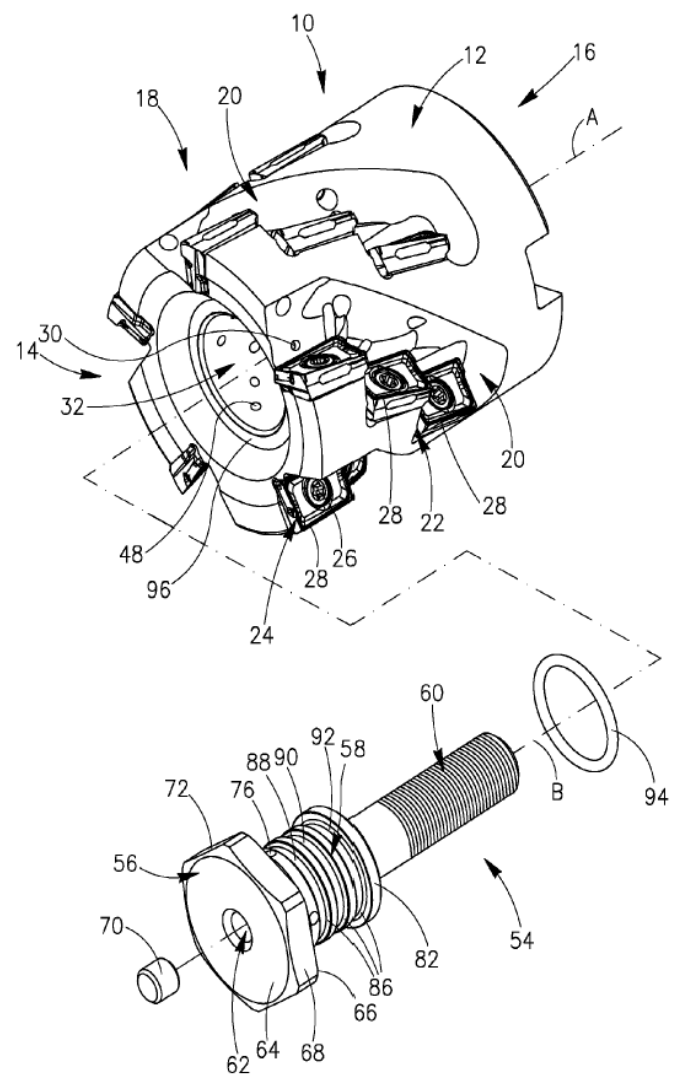

Fig. 5. Patent of tool with adjustable cooling [8] 
The invention CZ 306957 is based on a similar principle. It is a cutter which is attached to a chuck by means of a hollow screw equipped with a system for supplying coolant to the cutting point. The cutter thus has an internal fluid supply through the tool body and through the hollow screw, thus achieving more efficient cooling at the face and directly at the cutting point. However, this design of the tool does not allow for control in the form of partial closure of the cooling channels compared to the previous design. The design of the tool with the hollow locking screw is shown in the following figure. [10] [13]
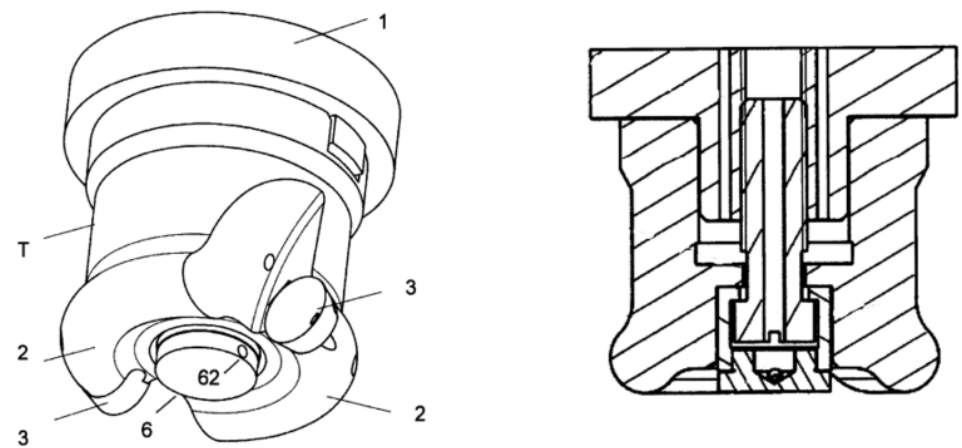

Fig. 6. Design of rotary tool with internal cooling [10]

A different view of coolant control is offered by patent US9434011.This patent addresses the "spray" nozzle that is located at the outlet of the coolant channel facing the face of the plate. The nozzle consists of an insert that is screwed into the body of the tool and then an adjustable nozzle itself with a slot-shaped outlet. The advantage of this nozzle design is both the two-axis adjustability and rotation and the slotted outlet shape. This makes it possible to direct the coolant directly to the cutting point and the entire length of the blade, thus achieving better cooling and chip breaking. [9]
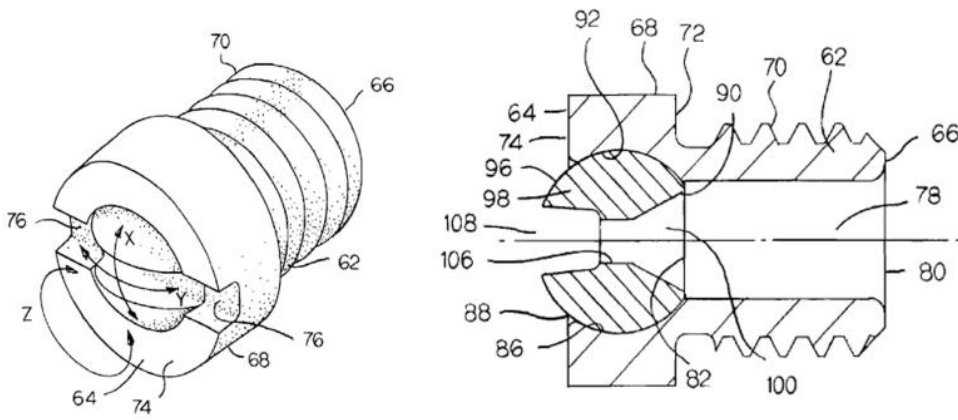

Fig. 7. Coolant spray nozzle [9]

Many other patents and inventions, such as US8573098B2 or US7125207B2, are based on the principle of feeding the cutting fluid through the central clamping screw. However, none of these solutions address the possibility of regulating the supply of cutting fluid to the cutting point, or the possibility of supplying fluid only to the face, only to the back, or both at the same time, depending on the need and method of machining. [11] [12]

\section{Prototype of a machining tool}

From the findings presented in the previous chapter, it is clear that additive technologies combined with topological optimization enables a new and completely different perspective on the design of machine tools. By using these technologies, it is possible to achieve improvements in tool properties, in particular in terms of addressing the cooling of the cutting edge of the tool, increasing its strength and stiffness, or improving its damping properties, for example. A major benefit of 3D printing is the ability to optimise the cooling channels, thus achieving the desired shapes and the supply of cutting fluid exactly to the cutting point with the desired channel pattern in the tool. Losses caused by, for example, perpendicular drilling of the channels or inaccurate direction of the cutting fluid are then eliminated. [15]

None of the tooling solutions analysed offers a combination of features and technical solutions that are suitable for use in hot runner machining. This means designing the tool to be able to use the full length of the cutting edge during machining, and to be able to mill and also possibly turn when fitted with the same inserts for both operations. For this reason, it is also necessary to regulate the cutting fluid supply, specifically the ability to close and open the cooling channels according to the required operation and other machining parameters. This is also related to the optimised coolant supply to the back and front of the insert along the entire length of its blade, precisely because of the use of the entire length of the blade. 
The second, and no less important, part is the optimisation of the tool design to increase its strength and reduce its susceptibility to instability in the cutting process, for example due to vibrations from the cutting forces. This can be achieved precisely on the basis of topological optimisation, where the design is designed to eliminate as far as possible the influence of cutting forces on the instability of the tool and the associated vibrations. [15]

On the basis of the obtained knowledge and the shortcomings identified from it, a prototype of a special tool was designed, especially for machining of hot spray. I participated in the development and design of this tool myself and also carried out and pre-experiments and experiments of NiCrBSi and $\mathrm{Fe} 13 \mathrm{Cr}$ spray machining. The tool will then be further optimized based on the evaluation of the experiments and machining experience of these injections. As already mentioned, the tool is designed for both milling and turning, for this reason it has a specific position of the interchangeable inserts in relation to the tool axis. This makes it possible to machine with a linear cutting edge and use the full length of the cutting edge. Thanks to additive technologies, it was possible to design the cooling channels with the smoothest possible flow so that there is no loss of fluid flow. Another advantage of using additive technology is the change in cross-section of the channels from an inlet circular to an outlet oval, which covers the entire length of the blade, a very important feature in linear cutting edge machining. The channels are also brought to the face and back of the insert for more efficient cooling. One of the main benefits is then the ability to regulate the coolant using the control elements on the side of the tool. With these members, it is possible to cool either the face/back or both at the same time, independently for each inserts separately according to the needs for the specific machining operation. Each control member therefore has four positions: all open, face only open, back only open and all closed. This makes it possible, for example, to open the cooling on only one insert in the case of turning, and thus achieve higher fluid pressure than when the cooling is also open on inserts that are not being machined. The following figures show the design of a prototype tool. [16] [17] [18]
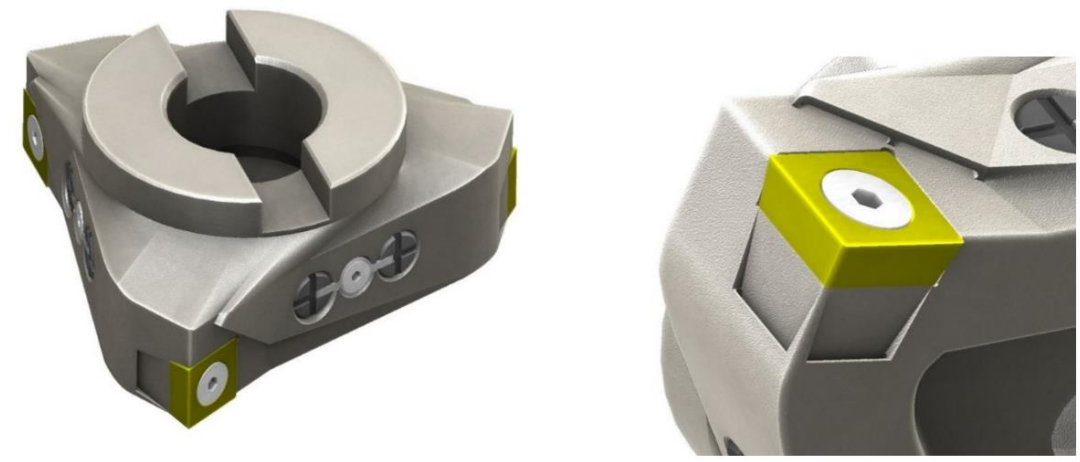

Fig. 8. prototype of tool
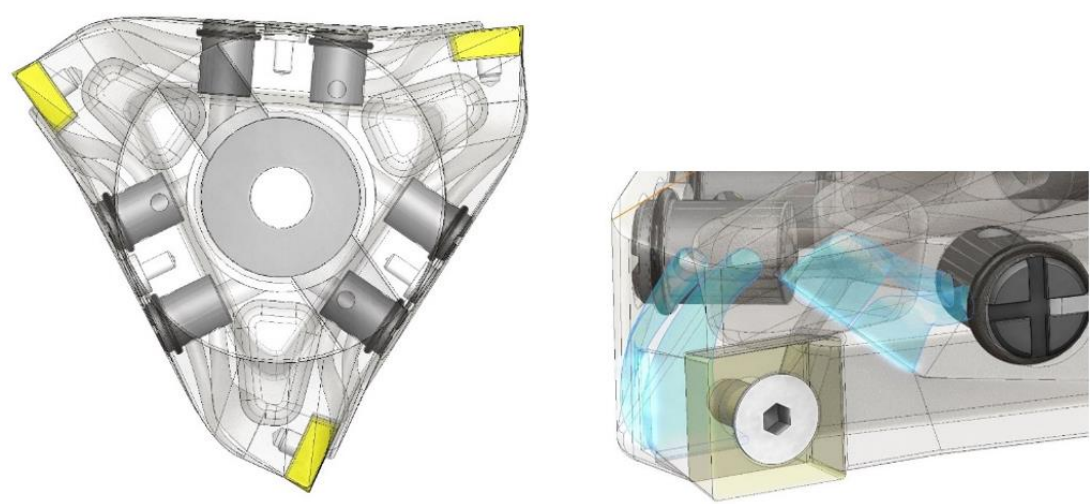

Fig. 9. Optimized channel guidance inside the tool

\section{Conclusion}

The main objective of the thesis was to elaborate the knowledge and introduction to the problem of design optimization. Due to the scope of the thesis, it does not contain a comprehensive view of the issue, but only a basic introduction to it. The review part is then devoted to the analysis of the current state and level in the field of development and design of tools using topological optimization and additive manufacturing, some part is also devoted to the solution of coolant supply to the cutting point and its possible regulation. On the basis of the research, the design of the tool design, evaluation of the knowledge and setting of objectives for the follow-up work, which will be focused on the development and design of the tool for machining not only for hot spraying, and on the experimental activities associated with it. The aim of the follow-up work will be to link the knowledge gained so far in the given issue and to deepen it. [17] [18] 


\section{Acknowledgments}

This article was created under the project SGS-2019-008: Research and Development for Innovation in the Field of Manufacturing Technology - Machining Technology III.

\section{References}

[1] Zatloukal, T., Řehoř, J., Fulemová, J. \& Povolný, M. (2020) Optimization of the machining process of NiCrBSi thermal spraying. In Annals of DAAAM and Proceedings of the International DAAAM Symposium. Vienna: DAAAM International Vienna, s. 632-637. ISBN: 978-3-902734-29-7, ISSN: 1726-9679

[2] Zatloukal, T., Gombár, M., Fulemová, J., Řehoř, J. \& Povolný, M. (2019) Optimization of the thermal spraying process depending on the surface roughnes. In Proceedings of the 30th International DAAAM Symposium "Intelligent Manufacturing \& Automation". Vienna: DAAAM International Vienna, s. 1026-1033. ISBN: 978-3902734-22-8, ISSN: 1726-9679

[3] Humár,A., (2004) „Technologie obrábění - 2.část,“ Brno 2004. [Online]. Available from: http://ust.fme.vutbr.cz/obrabeni/opory-save/TI_TO-2cast.pdf.

[4] https://www.sandvik.coromant.com. Accessed on: 2020-08-26

[5] https://www.additivemanufacturing.media/blog/post/am-is-advancing-into-tools-for-machining-examples-fromemo, (2020) Accessed on: 2020-08-27.

[6] https://rti.zcu.cz/export/sites/rti/dokumenty/dokumenty_public/KRAKEN-Special-light-milling-head.pdf (2020). Accessed on: 2020-08-26.

[7] https://rti.zcu.cz/laboratore/obrabeni/index.html (2020). Accessed on: 2020-08-26.

[8] Bonnarang, F. \& Christian, G. (2014) Rotary cutting tool having an adjustable cooling mechanism: US8696252. Available from: https://worldwide.espacenet.com/publicationDetails/biblio?DB=EPODOC\&II=0\& $\mathrm{ND}=3 \&$ adjacent $=$ true $\&$ locale $=$ enEP $\& F T=D \& C C=U S \& N R=8696252 B 2 \& K C=B 2$. Accessed on: 2020-08-26.

[9] Morrison, M., Verellen, J. \& Long, T. (2016) Coolant spray nozzle and cutter with coolant spray nozzle: US9434011. Available from: https://worldwide.espacenet.com/publicationDetails/biblio?DB=EPODOC\&II= $0 \& N D=3 \&$ adjacent $=$ true\&locale=en_EP\&FT $=$ D\&CC $=U S \& N R=9434011 B 2 \& K C=B 2$ (2020). Accessed on: 2020-08-27.

[10] Zetek, M. \& Schorník, V. (2016) Fréza s chlazením Available from: https://patentimages.storage.googleapis.com/78/72/15/79a7a0195505f4/CZ306910B6.pdf (2020). Accessed on: 2020-08-27.

[11] Craig, K., Long, T. \& Frota De Souza, F. (2004) Tool holder with integral coolant channel and locking screw therefor: US7125207B2. Available from: https://worldwide.espacenet.com/patent/search/family/ 035757578/publication/ US7125207B2?q=pn\%3DUS7125207B2\&queryLang=en\%3Ade\%3Afr Accessed on: 2020-08-27.

[12] Hoffer, B., Long, T. \& Frota De Souza, F. (2011) Cutting tool including a locking screw and adapter with coolant delivery: US8573098B2. Available from: https://worldwide.espacenet.com/patent/search/family/ 046705531/publication/US8573098B2?q=pn\%3DUS8573098B2\&queryLang=en\%3Ade\%3Afr. Accessed on: 2020-08-27.

[13] Hanzl, P. \& Zetková, I. (2019) Benefits of a new approach to designing milling cutter using Metal Additive Manufacturing, Published by Manufacturing Technology, ISSN 1213-2489, Vol. 18, No. 2

[14] Hanzl, P., Zetková, I. \& Daňa, M. (2018) Uniaxial Tensile Load of Lattice Structures Produced by Metal Additive Manufacturing. In ICKTI 2018 nové poznatky v technologiích a technologické informace '18 sborník př́spěvků. Ústí nad Labem, ČR: Ústav technologií a materíálů, Fakulta strojního inženýrství, Univerzita J. E. Purkyně v Ústí nad Labem, Česká republika, s. 57-61. ISBN 978-80-7561-114-7.

[15] Hanzl, P., Zetek, M., Rulc, V., Purš, H. \& Zetková, I. (2019) Finite Element Analysis of a Light-weight Milling Cutter for Metal Additive Manufacturing, Published by Manufacturing Technology, ISSN 1213-2489, October 2019, Vol. 19, No. 5, Pp. 753-758

[16] Zhang, W.; Jihong Z. \& Tong G. (2020). Topology Optimalization in Engineering Structure Desing. iSTE Press . ISBN 9781-178548-224-3.

[17] Liborius, H., Grund, T., Nestler, A., Paczkowski, G., Schubert, A., \& Lampke, T. (2021). Influence of the finishmachining by turning and diamond smoothing on the tribological properties of Fe $17 \mathrm{Cr} 2 \mathrm{Ni} 0.2 \mathrm{C}$ thermally sprayed coatings. Surface and Coatings Technology, 405 doi:10.1016/j.surfcoat.2020.126731

[18] Kim, S. H., \& Park, M. S. (2017). Improvement of STS316L milling characteristics according to coolant spray position. Transactions of the Korean Society of Mechanical Engineers, A, 41(5), 427-433. doi:10.3795/KSMEA.2017.41.5.427 